Lengua \& Sociedad, Revista de Lingüística Teórica y Aplicada

Vol. 19, n. ${ }^{\circ}$ 1, Lima, enero-junio de 2020, pp. 149-158

https://doi.org/10.15381/lengsoc.v19i1.22322

\title{
El tiempo pretérito en el castellano andino de niños bilingües de Ayacucho
}

\section{The past tense in Andean Spanish of bilingual children from Ayacucho}

\author{
Jorge Esquivel Villafana \\ Universidad Nacional Mayor de San Marcos, Lima, Perú \\ Grupo de Investigación Sociolin \\ https://orcid.org/oooo-0oo1-8940-0649 \\ jesquivelv@unmsm.edu.pe
}

\begin{abstract}
Resumen
En el presente trabajo se describe y caracteriza el empleo de las formas verbales pretéritas perfectas e imperfectas, con sus respectivas variantes modales, en el castellano hablado por los niños bilingües quechua-castellano del distrito de La Mar (Ayacucho).

Palabras claves: Castellano andino; morfosintaxis; transferencia gramatical; contacto de lenguas
\end{abstract}

\begin{abstract}
This work describes and characterizes the use of perfect and imperfect past verb forms, with their respective modal variants in the Spanish spoken by quechua-spanish bilingual children from La Mar district (Ayacucho).
\end{abstract}

Keywords: Andean Spanish; morphosyntax; grammatical transfer; language contact 


\section{Jorge Esquivel Villafana}

\section{Introducción}

El presente trabajo aborda el tratamiento del tiempo verbal pretérito en correlación con sus variantes aspectuales y modales en el castellano hablado por los niños del distrito de La Mar (Ayacucho). Parte de la consideración de que, en el paradigma de las formas verbales del español general, las categorías temporales de presente, pretérito y futuro de los modos verbales indicativo y subjuntivo constituyen referentes de oposición básicos, pues aluden a momentos diametralmente opuestos con relación al momento de la enunciación. Sin embargo, en esta variedad de castellano andino, se suele encontrar, característicamente, a nivel del modo verbal indicativo, el empleo alternado de los tiempos presente y pretérito imperfecto, sin preferencia alguna por el orden, sobre todo, en oraciones compuestas coordinadas de situaciones narrativas.

La descripción de los usos característicos del pretérito en esta variedad dialectal parte de la hipótesis de que el castellano hablado por los niños del distrito de La Mar (Ayacucho), zona bilingüe de contacto de lenguas (quechua - español), reporta un escaso control de las formas pretéritas e imperfectas.

Se propone como objetivo básico describir las manifestaciones temporomodales flexivas restringidas a las formas del pretérito y determinar los usos característicos en el habla de los niños de esta variedad de castellano. El corpus base se obtuvo a partir de entrevistas personales directas con los niños de entre ocho y diez años de edad de ambos géneros, las cuales fueron recogidas en cintas magnetofónicas durante los años 2016-2019 en el referido distrito, enclavado en la zona sur andina del Perú.

\section{Aspecto teórico}

El verbo es una categoría lexical variable que se constituye en el elemento primordial en la conformación de oración. Morfológicamente, comprende dos estructuras denominadas respectivamente lexema y morfemas gramaticales flexivos, los cuales conllevan los significados de persona, número, tiempo, modo y aspecto. Esta dimensión puede variar cuando se trata de las formas no personales, las cuales carecen de morfemas flexivos.

Los morfemas verbales suelen ser amalgamas o morfemas sintéticos, pues ellos expresan más de una categoría gramatical. Así, en cantaré, la forma -ré indica tiempo y modo. La categoría gramatical de tiempo permite precisar la significación verbal en un punto temporal determinado, pudiendo ser este el actual 
(presente): amo o no actual (pasado y futuro): amé y amaré. Fernández y Anula (1995); Carrasco (2016), entre otros, consideran, en términos rigurosos, no tanto momentos como los que hemos mencionado, sino la relación entre los momentos, que puede ser de anterioridad, simultaneidad y posterioridad; así se puede hablar de un primer momento, el de la enunciación, y un segundo momento, el de la referencia, relacionado directa e indirectamente con el primero. Desde esta perspectiva, las tres formas temporales, amo, amé y amaré indican situaciones de simultaneidad, anterioridad y posterioridad con respecto al momento de la enunciación.

A diferencia del tiempo actual, los no actuales (pasado y futuro) presentan, a su vez, una subclasificación que, en términos morfológicos, pueden ser los denominados tiempos simples y compuestos. En los tiempos simples toda la información del verbo se encuentra reunida en una sola forma verbal: amé; en los tiempos compuestos, la información está contenido en dos formas lexicales o perifrástica: el verbo auxiliar haber y el participio correspondiente del verbo principal o auxiliado: he amado.

La categoría de tiempo presente expresa la coexistencia de dos elementos: lo referido (con respecto a algo) y el momento de la enunciación. Es el momento temporal utilizado para expresar acontecimientos de duración indefinida (Bello, 1982: 200): "José es un hombre honesto». Incluso este puede ser utilizado para expresar hechos históricos: «Colón llega a América en 1492». El tiempo pretérito, en correlación con el aspecto verbal y el modo indicativo muestra dos formas: el perfecto e imperfecto. El pretérito perfecto describe el evento verbal en su versión de estado anterior al momento del habla: «Héctor jugó mal». El pretérito imperfecto expresa el hecho temporal de pasado con un rasgo aspectual de imperfecto o de acción no concluida; presenta la acción en su curso, sin aludir a su comienzo ni a su final: ellos jugaban mal. El tiempo futuro alude a hechos posteriores al momento del habla: «yo jugaré mañana».

La categoría de modo expresa la actitud del hablante con respecto al grado de realidad o irrealidad que le atribuye a la descripción de los sucesos (Fernández y Anula, 1995: 261). Se reconoce dos modos básicos: el indicativo, caracterizado por el rasgo [+ realidad], describe la certeza de un hecho real y objetivo; el subjuntivo, caracterizado por el rasgo [-realidad], describe el hecho subjetivamente, como una posibilidad, una probabilidad o duda de ocurrencia. El tercer modo, el imperativo, a diferencia de los dos anteriores, no hace referencia a la realidad, sino expresa una orden o mandato dirigido a una segunda persona (tú o ustedes) directamente. 


\section{Jorge Esquivel Villafana}

La categoría de aspecto conlleva la información acerca de la estructura interna de los sucesos descritos. Esta distingue la variación existente en el paradigma verbal entre dos tiempos del pasado o entre las estructuras formales simples y compuestas (amé y he amado), lo que se manifiesta mediante los rasgos [ \pm perfectivo]. La especificación positiva del rasgo, [+ perfectivo], indica que la acción verbal es vista como terminada, concluida; la especificación negativa [- perfectiva], indica que la acción verbal no ha llegado a su término, no ha concluido, permanece en desarrollo, ello independientemente de la localización temporal que puede estar expresada en pretérito o futuro. Así, todas las formas compuestas más el pretérito indefinido son [+ perfectivas]; y todas las simples, salvo la excepción referida son [- perfectivas]. De este modo, el aspecto puede estar expresado mediante un morfema amalgama con la carga de tiempo, modo y aspecto o mediante una perífrasis verbal.

Las categorías de número y persona son expresadas mediante un solo morfema en situación de sincretismo; ellas expresan la dualidad singular y plural y las personas gramaticales del discurso.

\section{El pretérito en el castellano andino}

\subsection{El pretérito perfecto simple}

De acuerdo con las definiciones gramaticales, el pretérito perfecto simple describe una situación en un punto de la línea temporal anterior al momento del habla (RAE, 2010: 441):

(1) a. Fui con mi sobrino al parque de Las Leyendas.

b. Mi abuelita vendió su chacra cuando estaba enferma.

c. Yo agarré tuna y naranjas y tiré en su cara.

d. Mi papá atrapó un leopardo; él atrapa animales.

Como se ve, este tiempo, al par que localiza la acción en un momento anterior al de la enunciación, le imprime también al evento el significado de situación completa, terminada, acabada. Cuando se dice «mi abuelita vendió su chacra...» se informa de una acción realizada en su plenitud, terminada; se habla de un hecho consumado que, en tanto no es inmediato, no tiene ninguna relación con el momento actual, es historia; el pretérito perfecto simple tampoco hace referencia 
El tiempo pretérito en el castellano andino de niños bilingües de Ayacucho

a acciones repetidas, a menos que un complemento de frecuencia aporte dicho significado: «después de breves encuentros, se reunieron todos los días» (RAE, 2010: 441).

\subsection{El pretérito perfecto compuesto}

En términos normativos, el pretérito perfecto compuesto denota el valor de pasado dentro del ámbito de la actualidad del hablante; esto es, en contraste con la forma anterior, este tiempo expresa situaciones concluidas inmediatamente anterior al momento del habla, de allí el valor de antepresente que se le atribuye. Con respecto a este caso concreto, Rojo y Veiga (1999: 2902) afirman que «su relación estrecha con el presente le permite cierta afinidad de rasgos deícticos mostrados entre el verbo auxiliar y algunos demostrativos». Así, por ejemplo, en la oración «este año hemos ganado dos trofeos», el demostrativo este, que temporalmente significa presente, concuerda en este rasgo con la estructura compuesta hemos ganado, pero no muestra esa afinidad con las formas demostrativas ese o aquel, cuyos significados aluden a tiempos pasados, intermedios o remotos. Ejemplos:

(2) a. Una señora nos ha invitado ese chuño.

b. El cóndor camina por arriba, vuela, lo hemos visto... Así da vueltas.

c. De una señora sus hijos se han escapado.

d. A mi chancho ha chupado sangre el murciélago.

Al lado de los ejemplos descritos, cuyas formas verbales compuestas responden a los significados del pretérito señalado, encontramos una variedad de ejemplos que indican una tendencia o preferencia marcada por el pretérito compuesto para significar todo tipo de acciones pasadas inmediatas o no. La dualidad inmediatez/ mediatez del evento verbal en relación con el momento de la enunciación se pierde en favor de la forma compuesta que, de este modo abarca toda la significación pretérita. Al respecto, es ilustrativa la afirmación de Cartagena (1999: 1950), quien al referirse al pretérito compuesto agrega que «de un empleo meramente resultativo en el ámbito del presente pasa, paulatinamente, a designar acciones concluidas en el pasado». Los ejemplos reunidos en (3) y (4) donde el empleo de los adjuntos temporales como ayer, un día, una vez, alguna vez, y de los locativos (en Lima, en el zoológico, en carnavales) imprimen a las oraciones significados de eventos remotos y lejanos, sugieren, por tanto, el empleo del pretérito perfecto simple; 


\section{Jorge Esquivel Villafana}

sin embargo, y como es característico en esta variedad dialectal, los encontramos expresados con las formas perifrástica o compuestas:

(3) a. Un día cuando lo hemos dejado (a la tortuga) tapado con tabla, se ha salido.

b. Alguna vez le he acompañado a mi mamá.

c. Alpacas he visto cuando hemos ido y...Ya me he olvidado.

(4) a. Su cabeza le han roto jugando carnaval.

b. Tortuga en el zoológico he visto.

c. Más allá, llegando a Lima, alpacas y vicuñas he visto.

A propósito, el ejemplo (5) ilustra, generosamente, la preferencia casi absoluta por este tipo de forma verbal en la narración de eventos pasados; este muestra en una sola oración la profusión de estas formas.

(5) Una señora se había asustado porque el cóndor se había volado y se había ido a otro árbol.

A manera de explicación de este fenómeno, consideramos que el profuso empleo de la forma del pretérito compuesto en desmedro del pretérito perfecto simple en el español de los niños de Ayacucho -zona bilingüe quechua-español ubicada en la zona surandina del Perú- encuentra fuerte soporte en los patrones estructurales de la lengua quechua, desde donde se da las transferencias gramaticales básicas hacia el español de los niños bilingües.

El quechua es una lengua aglutinante fuertemente dialectalizada. De acuerdo con las clasificaciones que de ella presentaron Alfredo Torero y Gary Parker, el quechua de Ayacucho pertenece al quechua A de Parker o quechua II de Torero, de la variedad quechua sureño o Chínchay. Junto con el cusqueño, son los dialectos más difundidos en el sur del Perú. La recolección de datos en el lugar se hizo mediante la entrevista directa. Por la naturaleza de la entrevista y el material empleado con esta finalidad, predomina en el corpus recogido el discurso narrativo.

En esta variedad de quechua, el tiempo pretérito se marca con los morfemas $-r(q) a$ y -sqa. El sufijo -rqa tiene como variante a -ra. Este morfema se añade directamente a la raíz verbal, antes de los sufijos de persona. Ejemplo: 
El tiempo pretérito en el castellano andino de niños bilingües de Ayacucho

(6) Yanu - rqa - ni 'Cociné'

Yanu - rqa - nki 'Cocinaste'

Yanu - rqa 'Cocinó'

El morfema -rqa tiene como variante libre a -ra:

(7) Yanurqani o yanurani 'Cociné'

Yanurqanki o yanuranki 'Cocinaste'

Yanurqa o yanura 'Cocinó'

Por otro lado, el morfema -sqa, también de pretérito, se utiliza específicamente para describir eventos narrativos, por lo que es llamado también morfema del tiempo narrativo (Soto, 1993).

(8) Ni-sqa-ni '(Yo) había dicho’

$N i-s q a-n k i$ '(Tú) habías dicho'

$N i-s q a$ '(Él) había dicho'

Como se aprecia, para la narración de los sucesos en el quechua, se utiliza el sufijo -sqa añadido a la raíz verbal, cuya glosa en el español equivale a una oración con el pretérito perfecto compuesto: había dicho. La preferencia por el empleo de esta forma en la descripción de los eventos narrativos por parte de los niños de la zona de Ayacucho puede entenderse como un fenómeno de transferencia, propio de un contexto de bilingüismo, donde las características gramaticales de la lengua materna, el quechua, son transferidas a la lengua castellana. Resta precisar que, de acuerdo con Merma (2007), el fenómeno de transferencia en una situación de contacto de lenguas, como es el caso que describimos, no es solo lingüístico sino también pragmático, pues el resultado de este proceso, que afecta la forma estándar de la segunda lengua, es propio de la aplicación de una serie de estrategias que utiliza el hablante para mostrar sus aptitudes y capacidades para producir mensajes.

\subsection{El pretérito imperfecto}

Normativamente, esta forma verbal describe los hechos pasados sin relación con el momento del habla. Desde esta perspectiva, las situaciones de tiempo pasado son vistas sin referencia a su inicio ni a su final. Así, en «Olga cantaba bien», se alude 


\section{Jorge Esquivel Villafana}

a un evento pasado que puede proyectarse hacia el presente, pues es probable que hasta hoy cante. Es denominado también copretérito, de acuerdo con la terminología de Bello (1982), pues es un pretérito coexistente con otro: «tú cantabas y yo tocaba la guitarra».

En la variedad de castellano que analizamos, encontramos usos del pretérito imperfecto compatibles con los del estándar; esto es, que característicamente expresan coexistencia temporal con otros verbos de tiempo pasado, de modo que se establece una relación de afinidad o de correlación con los hechos o situaciones pasadas:

(9) a. El cóndor en Ayacucho volaba, su pico era grande, tenía alas.

b. Osos he visto... Cuando caminaban, se movían sus piernas.

En la lengua española, las nociones temporales de presente, pasado o futuro establecen relaciones opositivas a partir de un punto de referencia, el de la enunciación o del habla; apréciese:

(10) a. Juan canta un vals.

b. Juan cantó un vals.

c. Juan cantará un vals.

Estas oposiciones fundamentales no indican el momento exacto en que se realiza la acción de cantar; pero sí informan, aunque no con precisión puntual, que estos eventos ocurrieron en el momento de la enunciación, antes de él u ocurrirán después.

En la variedad de español que analizamos, encontramos usos alternados de las formas verbales del pretérito imperfecto del indicativo con las del presente del mismo modo verbal (11a, b) o viceversa (11c, d), allí donde se esperaría encontrar formas verbales pretéritas en estricta concordancia; estos casos suelen darse en un entorno que resulta característico, el de las oraciones compuestas coordinadas:

(11) a. Nosotros teníamos plata... pagamos a los peones.

b. Los varones se vestían, así como las mujeres (en los carnavales); pero los capitanes se visten con anaranjado.

c. Primero le ponen globos, serpentinas (al árbol), todo le ponían.

d. Otros peones reclaman, le dábamos así. 
Como se observa en (11), no existe una correspondencia temporal ni aspectual entre los verbos alternantes de las cláusulas involucradas en las oraciones ejemplificadas. Se emplea a nivel del modo indicativo, tanto un verbo conjugado en presente en libre alternancia con un verbo conjugado en pretérito imperfecto, como un verbo conjugado en pretérito imperfecto en alternancia con un verbo en presente en situaciones narrativas de hechos del pasado en una misma estructura oracional. En este tipo de situaciones narrativas, el mantenimiento de la concordancia temporoaspectual parece irrelevante.

El pretérito imperfecto del subjuntivo. Las formas del pretérito del subjuntivo en el español general (cantara o cantase) carecen de presencia en esta variedad, pues no hemos encontrado un solo caso que signifique su empleo (parece ser que el uso de esta forma está restringido solo a la forma escrita de la lengua, según Borrego (1985)). En nuestro reporte del análisis, encontramos más bien que estas formas del pretérito están siendo sustituidas sistemáticamente por las formas del presente del subjuntivo (ame) en un contexto también común, el de las oraciones compuesta subordinadas. En la narración de los hechos descritos, el verbo de la cláusula subordinada no suele seguir el régimen temporal que la normativa exige, como se muestra en (12).

(12) a. Y pateábamos para que se seque (secara/secase) la coca.

b. De ahí su mamá agarraba para que sea (fuera/fuese) el baile bien bonito.

c. Maíz echábamos así, pa’ que seque (secara/secase).

\section{Conclusiones}

A partir de lo expuesto a lo largo del trabajo, se llegó a las siguientes conclusiones:

Con relación al pretérito perfecto. El pretérito perfecto simple registró escaso empleo. En la narración de los hechos pasados, el pretérito perfecto compuesto resultó la forma preferida. El significado de este abarca tanto los hechos mediatos, remotos, como los inmediatos de los sucesos narrados.

Con relación al pretérito imperfecto. Se registró el empleo alternado de las formas verbales del presente de indicativo con las del pretérito imperfecto o viceversa en las oraciones compuestas coordinadas; así como la sustitución sistemática de las formas pretéritas del subjuntivo por las del presente (seque por secara o 


\section{Jorge Esquivel Villafana}

secase). En este último caso, en la narración de los hechos ocurridos, es el verbo de la cláusula subordinada el involucrado en la discordancia del régimen temporal.

\section{Referencias bibliográficas}

Bello, A. (1982 [1847]). Gramática de la lengua castellana. Madrid: Edaf.

Borrego, J., Asencio, G., y Prieto, E. (1992). El subjuntivo valores y usos. Madrid: Sociedad General Española de Librería.

Cartagena, N. (1999). Los tiempos compuestos. En Real Academia Española. Gramática descriptiva de la lengua española. Síntesis. Madrid. pp. 2935-2975. Carrasco, Á. (2016). Las relaciones temporales interoracionales. En Javier Gutierrez (Ed.), Enciclopedia de Lingüística hispánica (pp. 139-151). Londres: Routledge Taylor and Francis Group.

Fernández, M., y Anula, A. (1995). Sintaxis y cognición. Introducción al conocimiento, el procesamiento y los déficits sintácticos. Madrid : Síntesis.

Merma, G. (2007). Contacto lingüistico entre el español y el quechua: un enfoque cognitivo-pragmático de las transferencias morfosintácticas en el español andino peruano (Tesis doctoral). Universidad de Alicante, España.

Real Academia Española. (2010). Nueva gramática de la lengua española. Madrid: Espasa.

Rojo, G., y Veiga, A. (1999). El tiempo verbal. Los tiempos simples. En Real Academia Española. Gramática descriptiva de la lengua española (pp. 28672934). Madrid: Síntesis.

Soto, C. (1993). Quechua. Manual de enseñanza. Lima: Instituto de Estudios Peruanos. 